\title{
NUMERICAL MODELLING OF MICRO-STRESSES IN CARBONISED AUSTENITIC CAST STEEL UNDER RAPID COOLING CONDITIONS
}

\begin{abstract}
The paper presents a method of the numerical modelling of micro-stresses in carbonised austenitic cast steel being developed during rapid cooling due to differences in the values of thermal expansion coefficients for this material phases - carbides and austenitic matrix. Micro-stresses are indicated as the main cause of crack initiation in the tooling elements of carburising furnaces being mainly made of austenitic cast steel. A calculation model of carbonised and thermally fatigued austenitic cast steel was developed based on the microstructure images obtained using light microscopy techniques and the phase composition evaluated with the X-ray diffraction method. The values of the stress tensor components and the reduced stress in the complex models of test material structure were determined numerically by the finite element method. The effort analysis was performed and the areas where development of cracks is to be expected were identified, which was experimentally confirmed.

Keywords: finite element method, micro-stresses, austenitic cast steel, carbides, fracture
\end{abstract}

\section{Introduction}

Carbonisation is one of the commonly used methods for hardening the surface layer of mechanical components. This process is carried out using the installations with furnaces being their main elements. The reliability of these furnaces depends on the durability of heat-resistant metal fittings used in them consisting of the elements fixed in furnaces as well as the tooling used for transporting the components being carbonised. A particularly low durability is characteristic of the tooling, which is associated with its participation at virtually all stages of the carbonisation process. These elements are exposed to almost parallel effects of high and variable temperature and carburising atmosphere, and, furthermore, additional loading exerted by the components being carbonised.

A major cause for decommissioning the carburising furnace tooling is its cracking $[1 \div 3]$ which, in extreme cases, induces its breaking apart into fragments. In the case of pusher furnaces being used in volume production, the tooling fragments being broken-off force the furnace to be taken out of service, their removal from the furnace chamber and all hardened components to be scrapped.

The tooling is most often made of austenitic cast steel, the structure of which is heterogeneous, with two phases being observed in it - elastic carbides and an elastic-plastic austenitic matrix. Differences in the physical properties of these two phases, especially in the values of their thermal expansion coefficients, are indicated as a source of stresses that lead to crack initiation in the tooling elements $[2,4 \div 7]$. In this study, the micro-stresses developing in carbonised austenitic cast steel during its rapid cooling were determined numerically with finite element method. The calculations were performed for the complex models of test material structure. The areas of these models where crack formation is to be expected were identified, which was experimentally confirmed.

\section{Elaboration of the material model}

\subsection{Investigation of the material microstructure}

The test material was austenitic steel cast of $\mathrm{Fe}-\mathrm{Ni}-\mathrm{Cr}-\mathrm{C}$ type of the following chemical composition (\% mass): $37.05 \%$ $\mathrm{Ni}, 16.10 \% \mathrm{Cr}, 0.19 \% \mathrm{C}, 1.35 \% \mathrm{Si}$, and $0.36 \% \mathrm{Mn}$ [2]. The samples being carbonised by the powder method, in a powder of the following composition: $\mathrm{BaCO}_{3}-11 \%, \mathrm{Na}_{2} \mathrm{CO}_{3}-4 \%$, charcoal $-85 \%$, in an electric Silit-rod-heated chamber furnace at $890^{\circ} \mathrm{C} \pm 10^{\circ} \mathrm{C}$ and $920^{\circ} \mathrm{C} \pm 10^{\circ} \mathrm{C}$ in 20 -hour cycles, were used for microscopic analyses [2]. The structure of austenitic steel cast being tested, and being characterised in the initial state by typical dendritic features, was transformed as a result of carbonisation. After carbonisation, a distinct carbonised layer could be identified in it, with a large number of carbides of a considerable size and a non-carbonised core with traces of the dendritic structure, where carbides are fewer and are characterised by a significantly smaller size (Fig. 1).

\footnotetext{
MARITIME UNIVERSITY OF SZCZECIN, INSTITUTE OF TRANSPORT ENGINEERING, 11 H. POBOZZNEGO STR. 70-507 SZCZECIN, POLAND

** POLISH NAVAL ACADEMY, INSTITUTE OF SHIP CONSTRUCTION AND OPERATION, 69 ŚMIDOWICZA STR., 81-127 GDYNIA, POLAND 

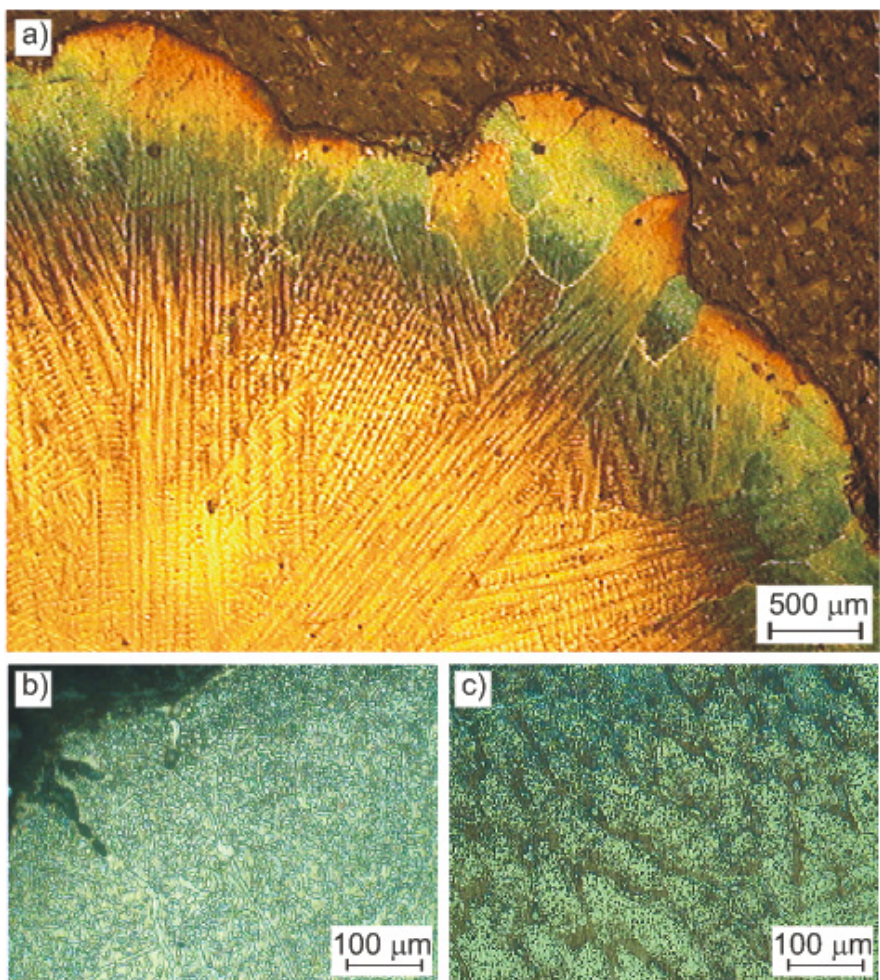

Fig. 1. Micro-structure of the carbonised layer in austenitic steel cast (light microscopy): a) cross-section through the entire carbonised layer and non-carbonised area, b) structure of carbonised area, c) structure of non-carbonised area

The phase composition of the tested austenitic steel cast in the carbonised layer and the non-carbonised core was assessed by the X-ray diffraction method on a Philips PW1710 $\mathrm{X}$-ray diffraction spectrometer using a Co lamp, $30 \mathrm{kV}$ voltage, $40 \mathrm{~mA}$ current, in the range of $2 \Theta$ angles from $20^{\circ}$ to $120^{\circ}$. In the alloy structure, the presence of two phases was observed, i.e. austenite $\gamma$ and $\mathrm{M}_{7} \mathrm{C}_{3}$ and $\mathrm{M}_{23} \mathrm{C}_{6}$ type carbides [5] located in it, with chromium being the predominant chemical element of their chemical composition [2].

As a place of crack initiation in the tooling being used in carburising furnaces is indicated the surface of these elements, i.e. the area where diffusion saturation with carbon is most intense, therefore only this area is referred to later in this paper.

During carbonisation, a scale may develop in the nearsurface area of austenitic steel cast, i.e. thin and brittle layers of $\mathrm{Cr}_{3} \mathrm{C}_{2}$ or $\mathrm{Cr}_{7} \mathrm{C}_{3}$ carbides as a result of the transformation of $\mathrm{Cr}_{2} \mathrm{O}_{3}$ oxides (no $\mathrm{Cr}_{3} \mathrm{C}_{2}$ carbides were found in the present case), as well as layers of $\mathrm{Cr}_{2} \mathrm{O}_{3}$ oxides developing as a result of oxidation when the carbonisation process is conducted improperly. In both cases, it should be expected that such layers will crack due to thermal shock. In the case of the austenitic steel cast being tested, the presence of carbide scale $\left(\mathrm{Cr}_{7} \mathrm{C}_{3}\right)$ was observed (Fig. 2).

Three specific areas can be identified in the micro-structure of the tested alloy: an area of compact and continuous carbide network, a precipitation free zone - austenite, and an area that holds the composite features, i.e. is composed of small carbide precipitates being surrounded by the austenitic matrix (Fig. 3).

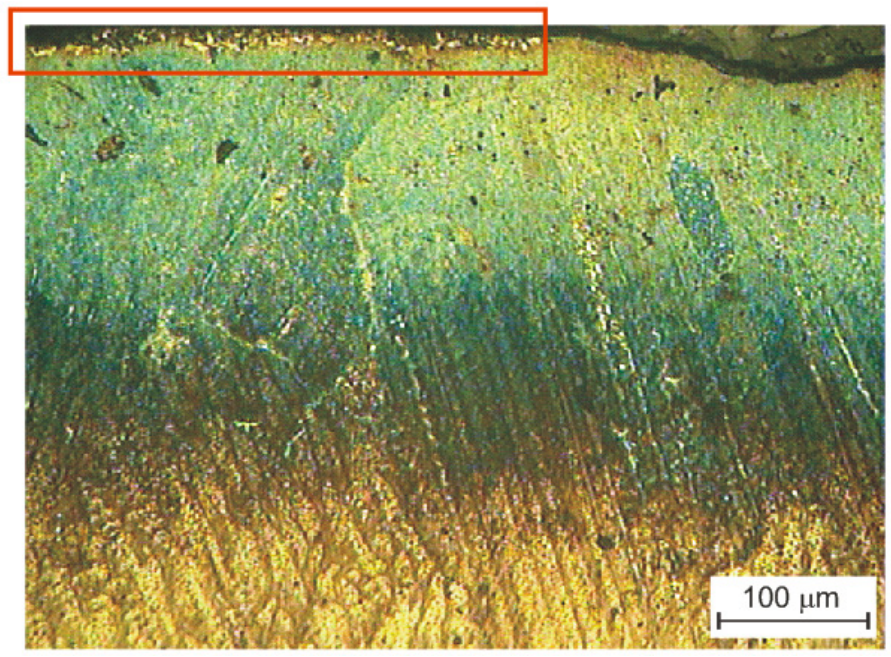

Fig. 2. Carbide scale $\left(\mathrm{Cr}_{7} \mathrm{C}_{3}\right)$ developing during carbonisation of the elements made of austenitic steel cast
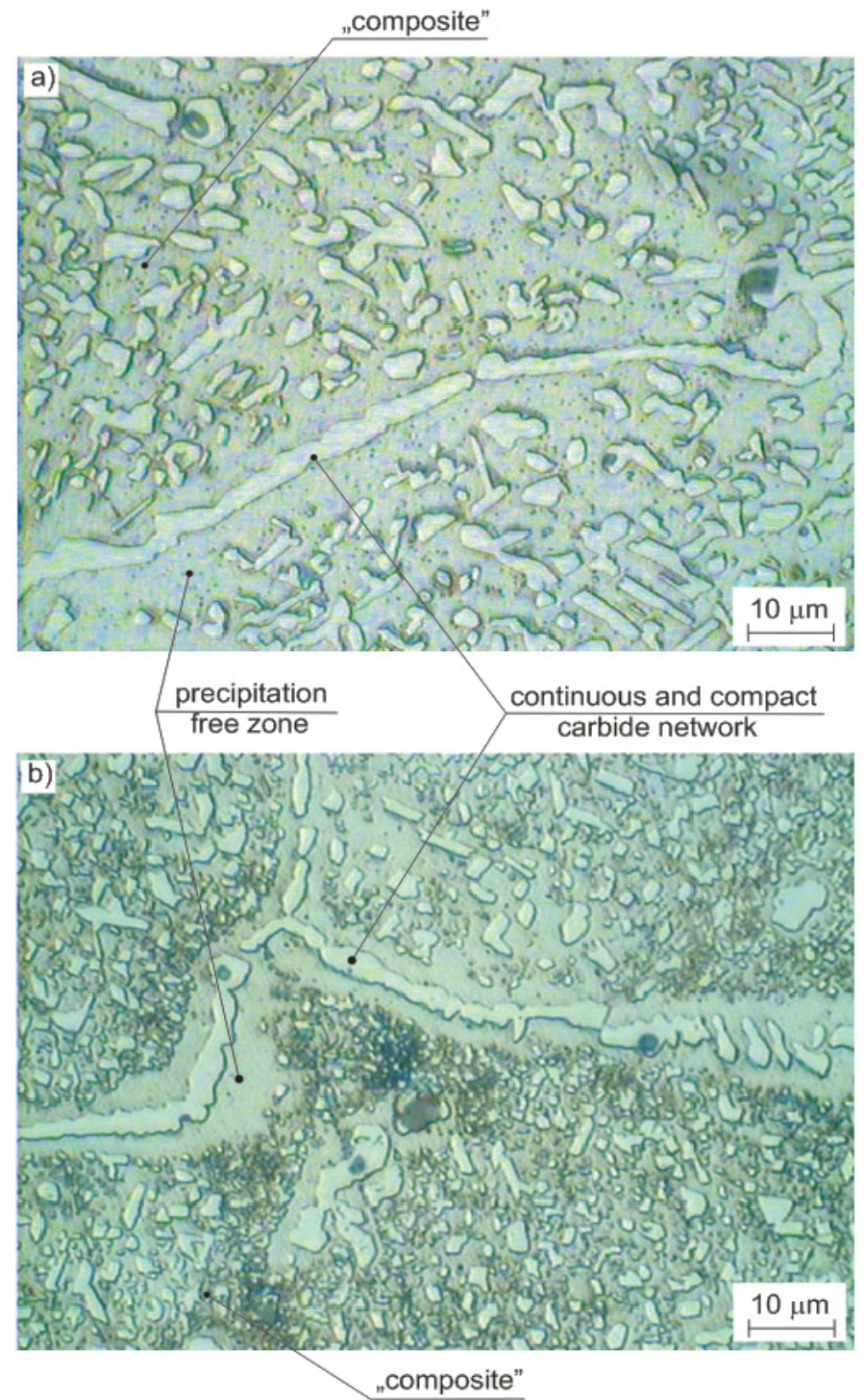

Fig. 3. Micro-structure of austenitic steel cast in different areas of the carbonised layer with characteristic areas being shown - a compact and continuous carbide network, a precipitation free zone, and an area of the "composite" structure: a) near-surface area of the carbonised layer, b) internal area of the carbonised layer 
The presence of precipitation free zone is the result of the ongoing carbonisation process. The need for supplying chromium to emerging carbides at the grain boundaries consequently leads to the formation of austenite areas where carbides are not present. The supply of chromium from the austenitic matrix also induces the transformation of $\mathrm{M}_{7} \mathrm{C}_{3}$ carbides into $\mathrm{M}_{23} \mathrm{C}_{6}$ carbides.

In the carbonised area, there are significant differences in the shape and size of carbides located at the grain boundaries and inside grains. The carbides inside austenite grains, being generally smaller, are similar in shape to spherical, cylindrical ellipsoidal or other more complex forms. By contrast, the carbides located at the grain boundaries are clearly larger and have different dimensions, i.e. their length and height is several times greater than their width, which makes them to be similar in shape to cuboidal plates.

\subsection{Model of material microstructure and properties}

It was assumed in the calculation model for the microstructure of austenitic steel cast being tested that carbides at the grain boundaries, corresponding in shape to cuboidal plates and the largest and virtually continuous at the surface, reduce their dimensions when moving into the material to the less carbonised area and lose their continuity at the same time. The carbides located inside grains, most often spherical or ellipsoidal in shape, have considerably smaller dimensions compared to those being located at the grain boundaries. Geometric parameters of the calculation models were adopted based on the obtained microscopic images.

The area separating carbides at the grain boundaries and inside grains is a precipitation free zone. Some of the grains located closest to the "alloy surface" may have fragments which are left uncovered by the austenitic matrix. The ongoing oxidation or carbonisation processes make the carbides "coming out" onto the "alloy surface" to be possibly covered by a layer of $\mathrm{Cr}_{2} \mathrm{O}_{3}$ oxides or $\mathrm{M}_{7} \mathrm{C}_{3}$ carbides, despite not being covered by the austenitic matrix.

The calculation model that takes into account the above assumptions is presented in Figure 4.

It was assumed for the calculations that carbides $\left(\mathrm{M}_{7} \mathrm{C}_{3}\right.$ and $\left.\mathrm{M}_{23} \mathrm{C}_{6}\right)$, like chromium oxides $\left(\mathrm{Cr}_{2} \mathrm{O}_{3}\right)$, are elastic materials in the whole range of temperature changes, whereas austenite $\gamma$ is an elastic-plastic material with linearised hardening. The material constants adopted for calculations are summarised in Table 1.

TABLE 1

Material constants adopted for calculations [2,8-12]

\begin{tabular}{cccccccc}
\hline Phase & $\begin{array}{c}\mathrm{E} \cdot 10^{5}, \\
\mathrm{~N} \cdot \mathrm{mm}^{-2}\end{array}$ & $\begin{array}{c}\mathrm{v}, \\
-\end{array}$ & $\begin{array}{c}\alpha \cdot 10^{-6}, \\
\mathrm{~K}^{-1}\end{array}$ & $\begin{array}{c}\mathrm{R}_{\mathrm{m}}, \\
\mathrm{N} \cdot \mathrm{mm}^{-2}\end{array}$ & $\begin{array}{c}\mathrm{R}_{\mathrm{c}}, \\
\mathrm{N} \cdot \mathrm{mm}^{-2}\end{array}$ & $\begin{array}{c}\mathrm{R}_{\mathrm{p} 0.2,}, \\
\mathrm{~N} \cdot \mathrm{mm}^{-2}\end{array}$ & $\begin{array}{c}\mathrm{E}_{\cdot} \cdot 10^{3}, \\
\mathrm{~N} \cdot \mathrm{mm}^{-2}\end{array}$ \\
\hline $\begin{array}{c}\text { Carbides } \\
\mathrm{M}_{7} \mathrm{C}_{3}\end{array}$ & 2.94 & 0.372 & 10.9 & 252 & 3100 & - & - \\
\hline $\begin{array}{c}\text { Carbides } \\
\mathrm{M}_{23} \mathrm{C}_{6}\end{array}$ & 1.998 & 0.367 & 10.5 & 252 & 3100 & - & - \\
\hline Austenite & 1.73 & 0.253 & 15.1 & - & - & 208 & 4.09 \\
\hline
\end{tabular}

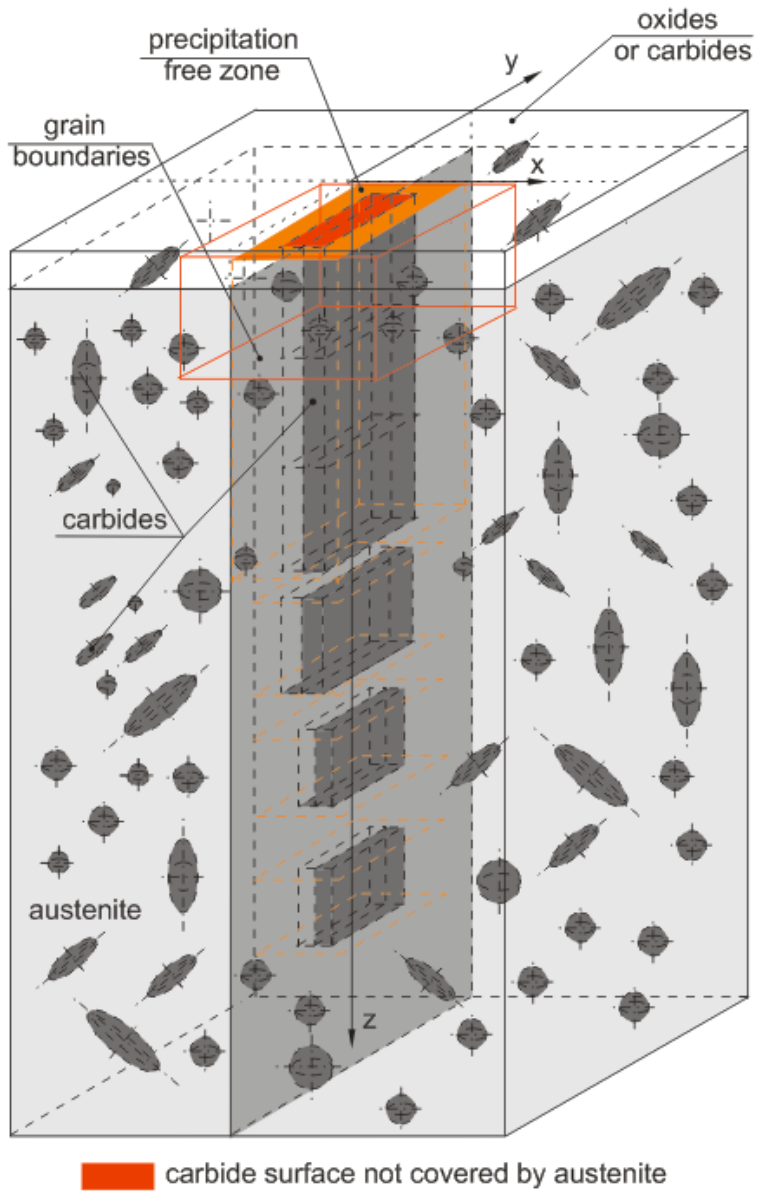

Fig. 4. Calculation model for the structure of carbonised austenitic steel cast with a carbide at the grain boundaries being the closest to the "alloy surface" partially covered by the austenitic matrix

The coefficients of thermal expansion $\alpha$ for $\mathrm{M}_{7} \mathrm{C}_{3}$ carbides and austenite $\gamma$ for a temperature higher than $20^{\circ} \mathrm{C}$ were determined based on the relationships being described in the other papers $[2,13,14]$. The hardening module $\mathrm{E}_{\mathrm{e}}$ for austenite $\gamma$ was adopted based on the hardening module for $17 \% \mathrm{Cr}-36 \% \mathrm{Ni}$ austenitic steel cast being saturated for 3 hours at $1100^{\circ} \mathrm{C}$ and cooled in water [2].

\section{Numerical evaluation of stress distribution in the modelled material}

Calculations were performed using ANSYS finite element software package; in all the analysed cases, discretisation of the calculation models was made using the twenty-node finite elements SOLID-95.

In order to perform accurate calculations at the optimal time while preserving the features of complex models, a segment of the model presented in Figure 4, marked in red, composed of the following carbides: a cuboidal carbide "coming out" onto the "alloy surface" and four spherical carbides separated from the former by a precipitation free zone, of different diameter and size, being located in the grains, the dimensions of which 
and the distances among which are presented in Figure 5a, was adopted for calculations.

It was assumed for calculations that the model is rapidly cooled in the temperature range $700^{\circ} \mathrm{C}-20^{\circ} \mathrm{C}$, while a change in temperature occurs simultaneously in the entire volume of the alloy. The symmetry of the calculation model enabled the performace of calculations for its quadrant (Fig. 5b). Symmetric boundary conditions on respective surfaces and the method of discretisation of the model are presented in Figures $5 \mathrm{~b}$ and $5 \mathrm{c}$. Calculations were performed for the $\mathrm{M}_{7} \mathrm{C}_{3}$ type carbides.

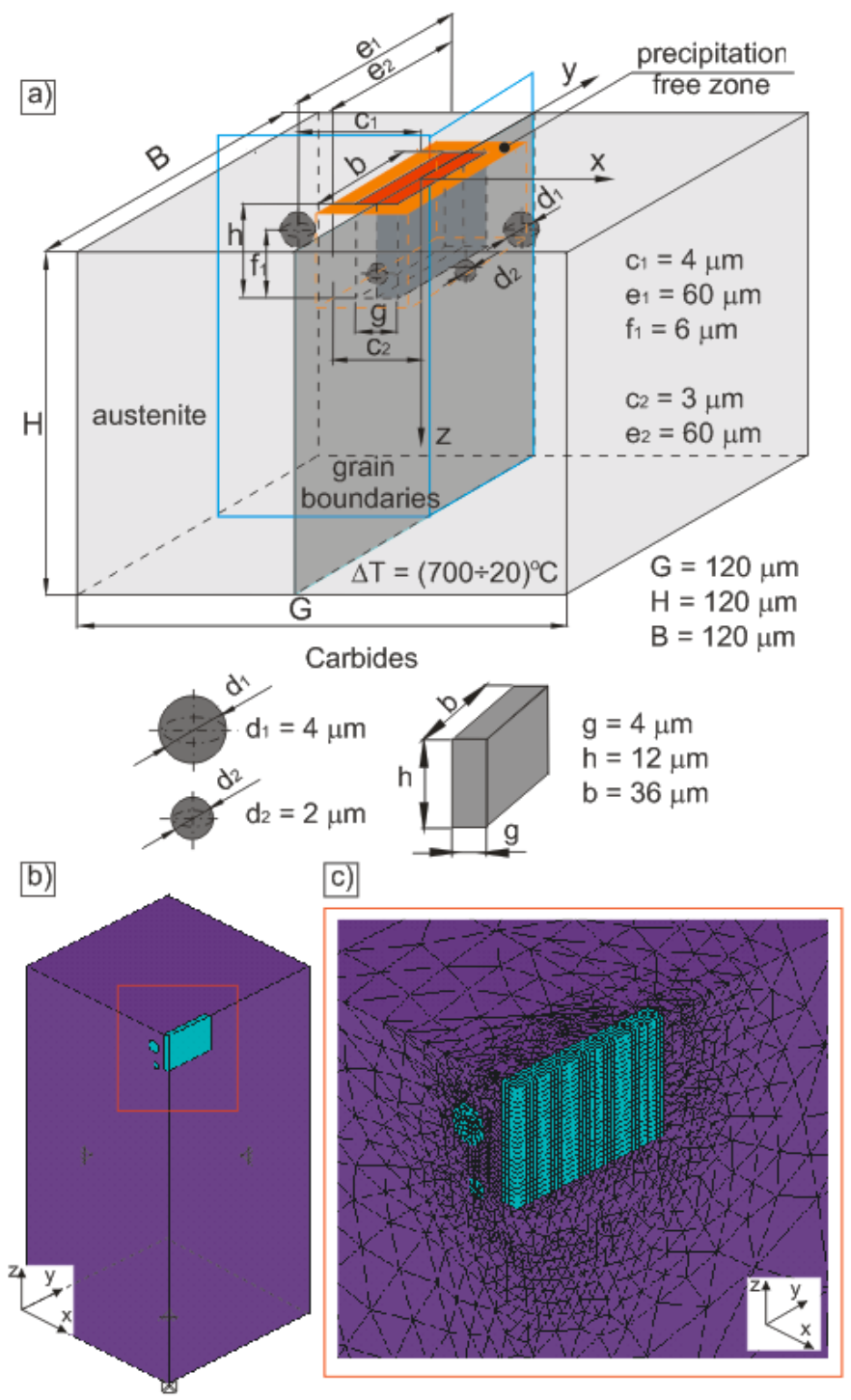

Fig. 5. Calculation model for the micro-structure composed of a cuboidshaped carbide "coming out" onto the "alloy surface" separated by a precipitation free zone from four spherical carbides of different diameter and size being located in grains: a) structure model, b) calculation model, c) discretisation method

The distributions of the stress components $\sigma_{\mathrm{x}}, \sigma_{\mathrm{y}}, \sigma_{\mathrm{z}}, \tau_{\mathrm{xy}}, \tau_{\mathrm{yz}}$, $\tau_{\mathrm{xz}}$, being determined presented graphically in Figure 6 , show that spherical carbides completely surrounded by the austenitic matrix, irrespective of their size and distance from other carbides, are compressed - all stresses being determined in them were negative (-). In the case of cuboidal carbide, the distributions of stress components were different - it was also compressed but only in the areas being located at a distance from the "alloy surface". In its area directly "coming out" onto the "alloy surface" to a depth of about $3 \mu \mathrm{m}$, a sign of one of the tensor components of the stress $\sigma_{\mathrm{x}}$ changed from negative $(-)$ to positive $(+)$, which indicates the expansion of carbide in this area.
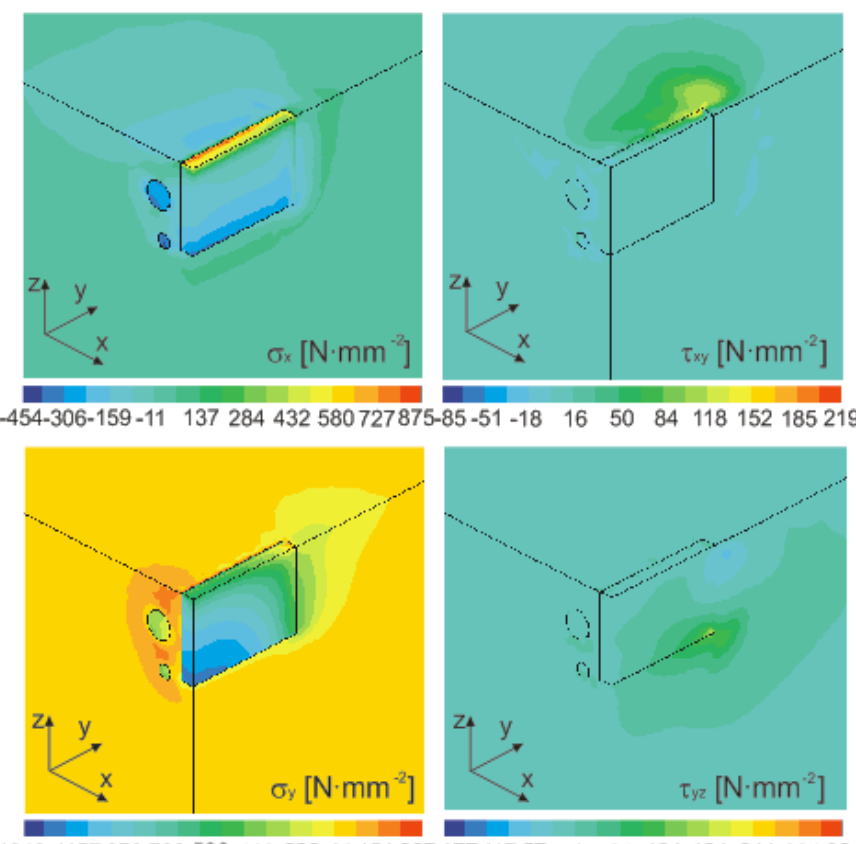

-1343-1157-970-783-596-410-223-36151 337-177-117-57 $4 \quad 64124184244304364$
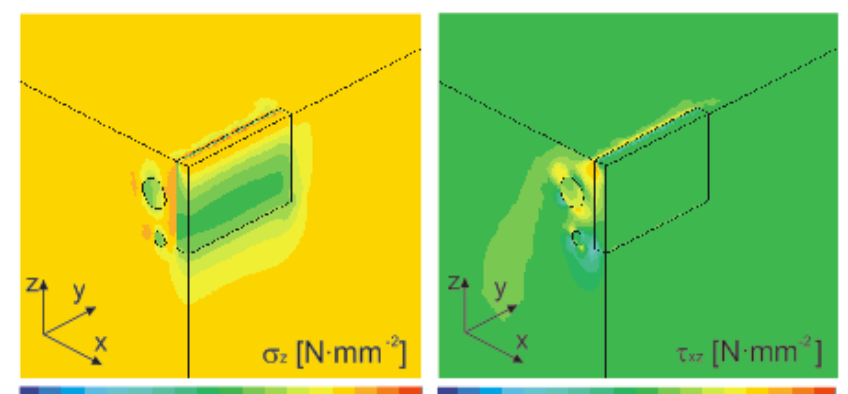

-1187-1020-853-687-520-353-187-20147313-265-212-158-104-51 $3 \quad 57 \quad 111164218$

Fig. 6. Distributions of the stresses $\sigma_{\mathrm{x}}, \sigma_{\mathrm{y}}, \sigma_{\mathrm{z}}, \tau_{\mathrm{xy}}, \tau_{\mathrm{yz}}, \tau_{\mathrm{xz}}$ in the calculation model of the micro-structure being composed of a cuboidal carbide "coming out" onto the "alloy surface" separated by a precipitation free zone form four spherical carbides of different diameter and size being located in grains

The reduced stresses $\sigma_{\text {redmax }}$ determined on the basis of the hypothesis of maximum normal stress $\sigma_{\text {redmax }}[15]$ in the carbides being completely surrounded by the austenitic matrix and in a substantial part of the carbide of cuboidal plate shape in the area located at a distance from the "alloy surface" did not exceed the compressive strength $\mathrm{R}_{\mathrm{c}}$ of such carbides (Fig. 7a).

In the near-surface area of cuboidal carbide, to a depth of about $1 \mu \mathrm{m}$, the determined values of reduced stresses $\sigma_{\text {redmax }}$ exceeded the tensile strength $R_{m}$ of carbides, which indicates the possibility of damage in this area. The fact that the highest values of tensile stresses do not occur in the axis of cuboidal carbide but in its area being adjacent to the boundary of carbide-austenitic matrix phases should be also emphasised. 


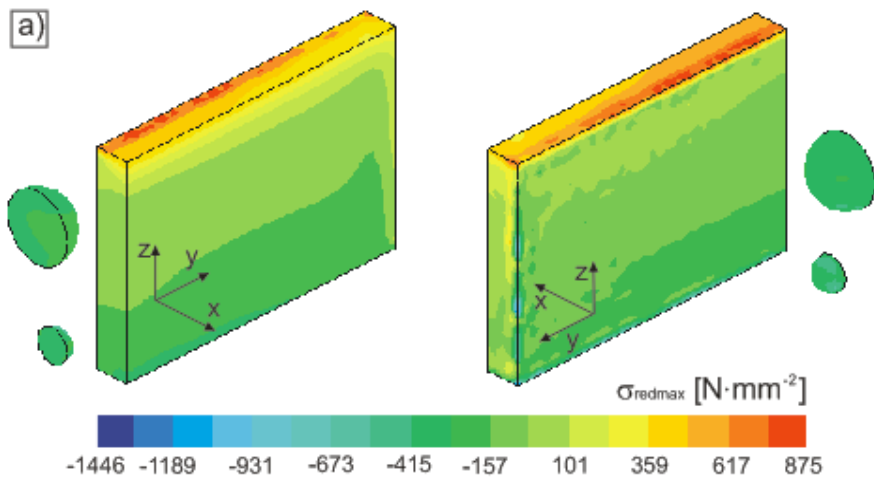

b)

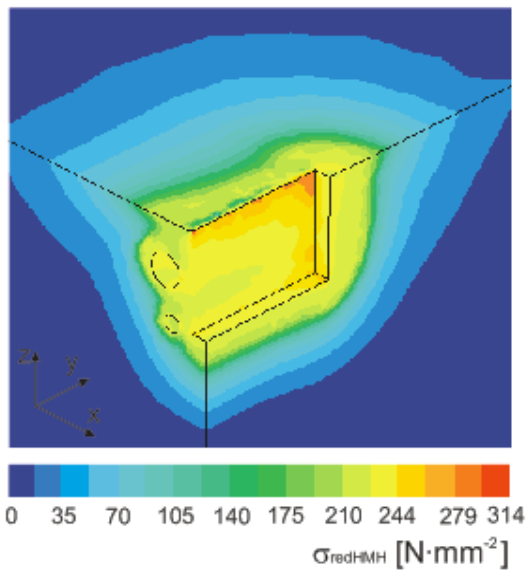

Fig. 7. Distributions of the reduced stresses $\sigma_{\text {red }}$ in the complex microstructure calculation model: a) in carbide - determined on the basis of the maximum normal stress $\sigma_{\text {redmax }}$ hypothesis, b) in austenite - determined on the basis of the Huber-von Mises-Hencky $\sigma_{\text {redHMH }}$ hypothesis

The distributions of stress components $\sigma_{\mathrm{x}}, \sigma_{\mathrm{y}}, \sigma_{\mathrm{z}}, \tau_{\mathrm{xy}}, \tau_{\mathrm{yz}}, \tau_{\mathrm{xz}}$ and the reduced stresses $\sigma_{\text {redHMH }}$ being determined on the basis of the Huber-von Mises-Hencky's hypothesis in the austenitic matrix [15] indicate the formation of permanent deformations in it in the areas being immediately adjacent to carbides (Fig. 7b). At a distance to about $2 \mu \mathrm{m}$ from carbides, the values of the reduced stress $\sigma_{\text {redHMH }}$ being determined exceeded the yield point $\mathrm{R}_{\mathrm{p} 0.2}$ of austenite. In the case of the carbides being adjacent to each other, the areas of permanent deformations overlap.

Under actual operating conditions, the carbides being located at the grain boundaries may be covered by a layer of carbide or oxide scale, the presence of which has been explained above. The next complex model of austenitic steel cast structure included the occurrence of carbide scale $\left(\mathrm{Cr}_{7} \mathrm{C}_{3}\right)$ and the presence of two grain boundaries with cuboidal carbides in their two possible locations. The carbide that "came out" onto the "alloy surface" in the previous model was covered by the $\mathrm{Cr}_{7} \mathrm{C}_{3}$ carbide scale. For comparison, the carbide being also located at the grain boundary but completely covered by the austenitic matrix and additionally by a layer of carbide scale $\left(\mathrm{Cr}_{7} \mathrm{C}_{3}\right)$ was also introduced (Fig. 8a).

The structure model with adopted dimensions, the method of its discretisation, and the symmetric boundary conditions are presented in Figure 8.
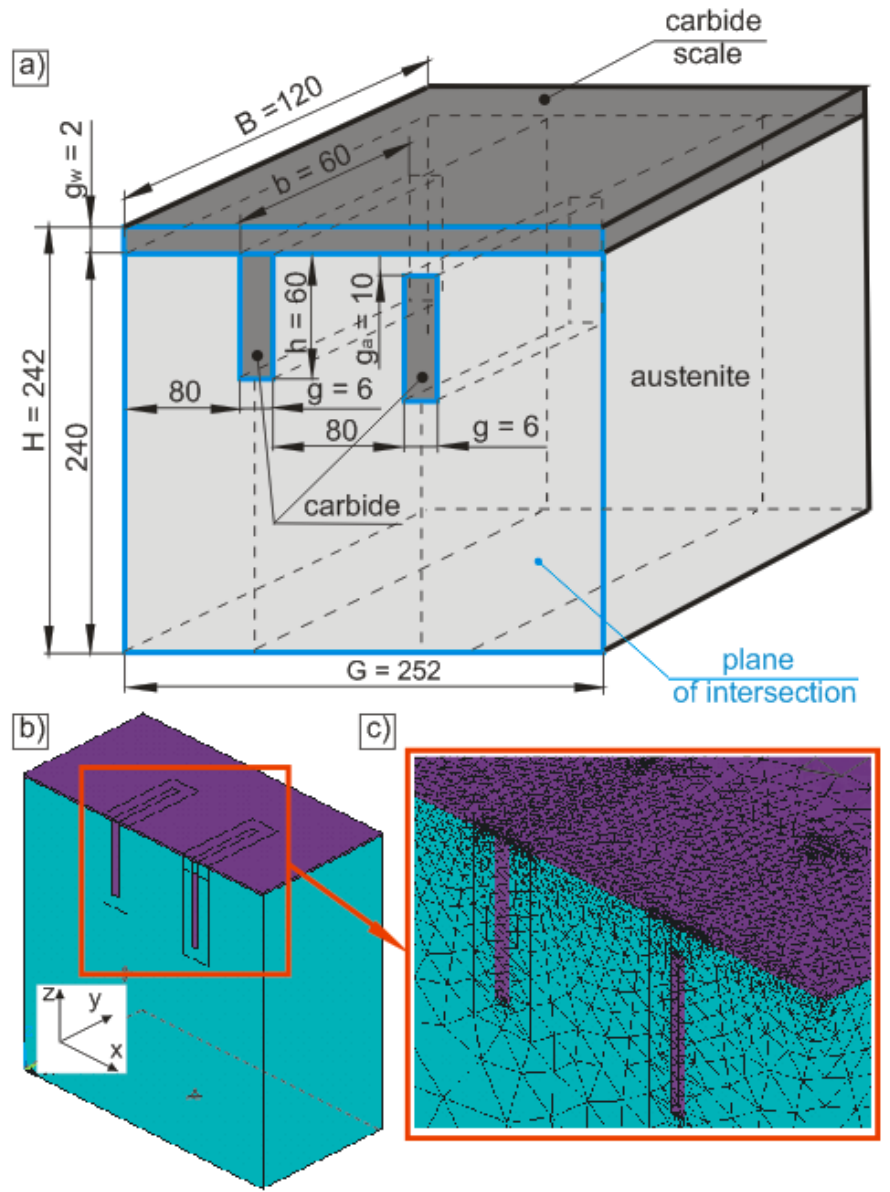

Fig. 8. Calculation model of the micro-structure composed of cuboidal carbides being partially and completely surrounded by the austenitic matrix and additionally covered by the $\mathrm{Cr}_{7} \mathrm{C}_{3}$ carbide scale: a) structure model, b) calculation model, c) discretisation method

Due to the symmetry of the analysed model, calculations were performed for its half - the plane of intersection is marked on Figure 8a.

In order to reproduce actual conditions, i.e. a continuous and compact carbide network, and ensure a right distance between the grain boundaries to eliminate the effect of overlapping of the stresses being formed within grains, the model dimensions were changed. In the case of carbides, the following dimensions were adopted: thickness $\mathrm{g}=6 \mu \mathrm{m}$, length $\mathrm{b}=120 \mu \mathrm{m}$, and height $\mathrm{h}=60 \mu \mathrm{m}$, with the external dimensions of the whole model being as follows: $\mathrm{G}=252 \mu \mathrm{m}, \mathrm{B}=240 \mu \mathrm{m}$, and $\mathrm{H}=242 \mu \mathrm{m}$. The carbide being completely covered by the austenitic matrix was under a layer of austenite with a thickness $\mathrm{g}_{\mathrm{a}}=10 \mu \mathrm{m}$, whereas the carbides and the austenitic matrix were covered by the $\mathrm{Cr}_{7} \mathrm{C}_{3}$ carbide scale with a thickness $g_{w}=2 \mu \mathrm{m}$.

Calculations were performed for the case of rapid cooling in the temperature range $900^{\circ} \mathrm{C}-20^{\circ} \mathrm{C}$, assuming that a change in temperature occurs simultaneously in the entire model volume.

The distributions of the stress components $\sigma_{\mathrm{x}}, \sigma_{\mathrm{y}}, \sigma_{\mathrm{z}}, \tau_{\mathrm{xy}}, \tau_{\mathrm{yz}}$, $\tau_{\mathrm{xz}}$ being determined during the cooling for the adopted calculation model are presented in Figure 9.

The distributions of the stress components $\sigma_{\mathrm{x}}, \sigma_{\mathrm{y}}, \sigma_{\mathrm{z}}, \tau_{\mathrm{xy}}$, $\tau_{\mathrm{yz}}, \tau_{\mathrm{xz}}$ being determined for the adopted calculation model with 


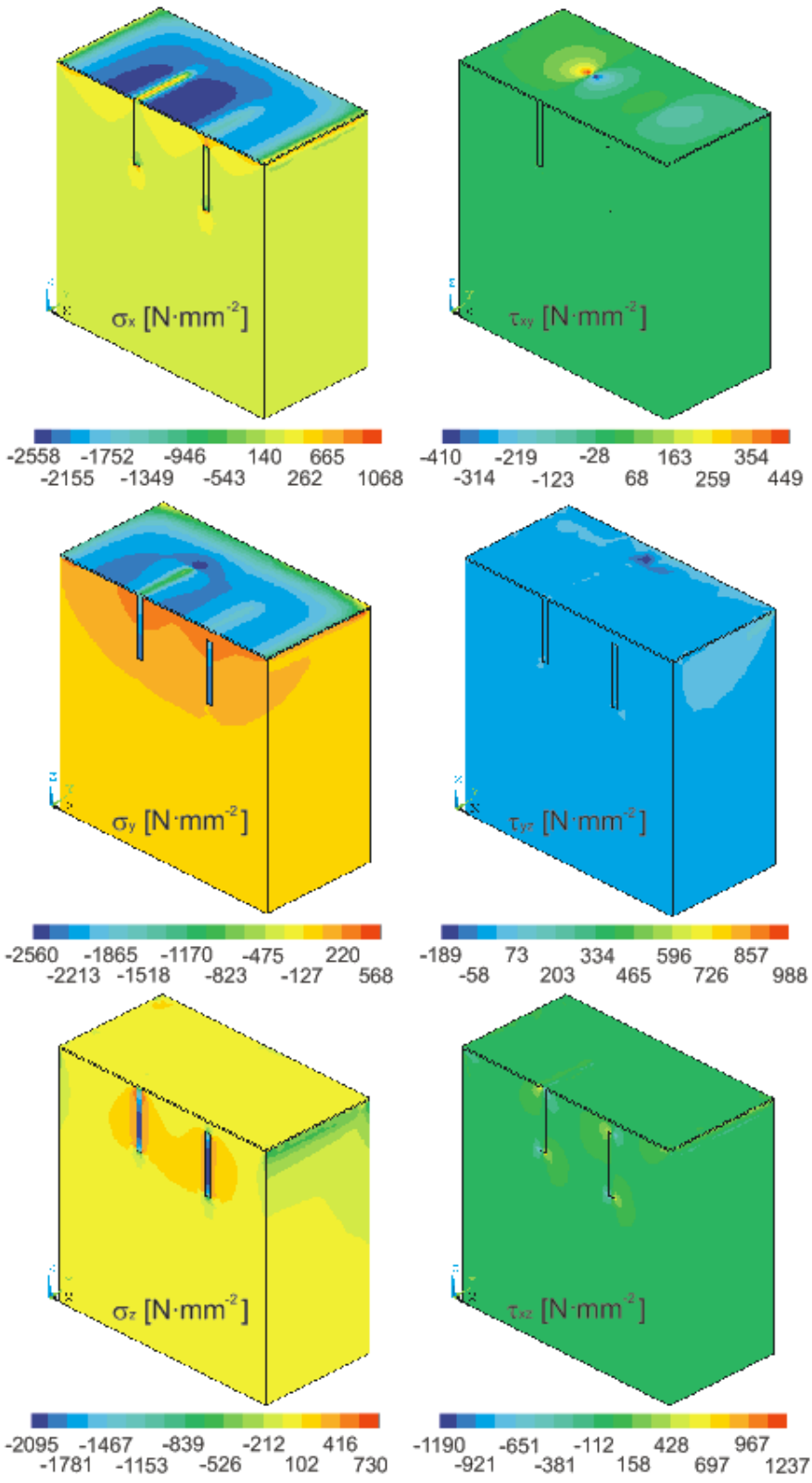

Fig. 9. Distributions of the stress components $\sigma_{\mathrm{x}}, \sigma_{\mathrm{y}}, \sigma_{\mathrm{z}}, \tau_{\mathrm{xy}}, \tau_{\mathrm{yz}}, \tau_{\mathrm{xz}}$ in the micro-structure model composed of cuboidal carbides being partially and completely surrounded by the austenitic matrix and covered by the $\mathrm{Cr}_{7} \mathrm{C}_{3}$ carbide scale during the cooling in the temperature range $900^{\circ} \mathrm{C}-20^{\circ} \mathrm{C}$

the layer of carbide scale being taken into account show that the scale is compressed during the cooling. The only area which significantly differs from this scheme is the scale area being located directly above the cuboidal carbide. In the carbides and the scale, the reduced stresses $\sigma_{\text {redmax }}$ were determined on the basis of the hypothesis of maximum normal stress $\sigma_{\max }$, like in the model being analysed above (Fig. 10).

During the cooling, there were considerable tensile stresses in the scale area being directly located over the carbide. The values of the reduced stresses $\sigma_{\text {redmax }}$ being determined in this area significantly exceeded the tensile strength $R_{m}$ of the $M_{7} C_{3}$, type carbides, which indicates the possibility of the scale layer tearing towards the axis $0 \mathrm{x}$ and the same the possibility of crack initiation.

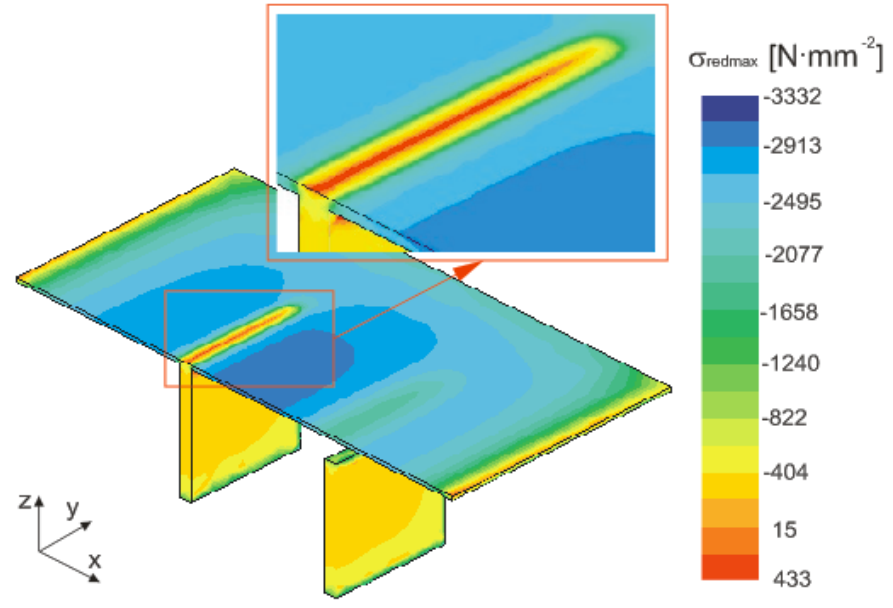

Fig. 10. Distribution of the reduced stresses $\sigma_{\text {redmax }}$ in the layer of $\mathrm{Cr}_{7} \mathrm{C}_{3}$ carbide scale and $\mathrm{Cr}_{7} \mathrm{C}_{3}$ carbides during the cooling in the temperature range $900^{\circ} \mathrm{C}-20^{\circ} \mathrm{C}$

The fact that the highest values of tensile stresses occur in the case of the cuboidal carbide being located directly under the scale layer in its axis, differently than in the model being examined above, should also be emphasised.

In the case of the cuboidal carbide being additionally separated from the carbide scale layer by austenite, all determined stresses over this carbide in the scale were compressive ones, with a value not exceeding its compressive strength $R_{c}$.

\section{Experimental verification of the cracks location in the thermally fatigued carbonised austenitic cast steel}

A sample, the shape of which corresponded to a half-rib being used in basic pallets that are commonly applied as elements of the carburising furnace tooling (Fig. 10a), was used in the experiment. The method of its carbonisation has been described in detail in the paper [2]. The carbonised rib was exposed to thermal fatigue, the cycle of which consisted of heating in an electric oven to $900^{\circ} \mathrm{C} \pm 5^{\circ} \mathrm{C}$, heat soaking in this temperature for 30 minutes, and rapid cooling in water with a forced circulation at $20^{\circ} \mathrm{C}$. In total, 75 cycles of thermal fatigue were performed, the result of which was crack formation in the sample (Fig. 11b-d). The method of thermal fatigue test for the tested rib has been described in detail in the paper [2].

On the surface of the tested rib being directly exposed to the effects of carburising atmosphere as well as inside the cracks, there is an area of clearly different characteristics, i.e. a zone of corrosive impact (Fig. 11b). The cracks in the tested sample extended only on the grain boundaries perpendicularly or at various angles to the sample edge and their length varied. The crack micro-structures being obtained clearly show that the area through which the cracks extend is the grain boundaries only (Fig. 11b,c,d). In addition, the fact that the cracks extended only through the carbides being located at the grain boundaries (Fig. 11c,d) should be emphasised. 

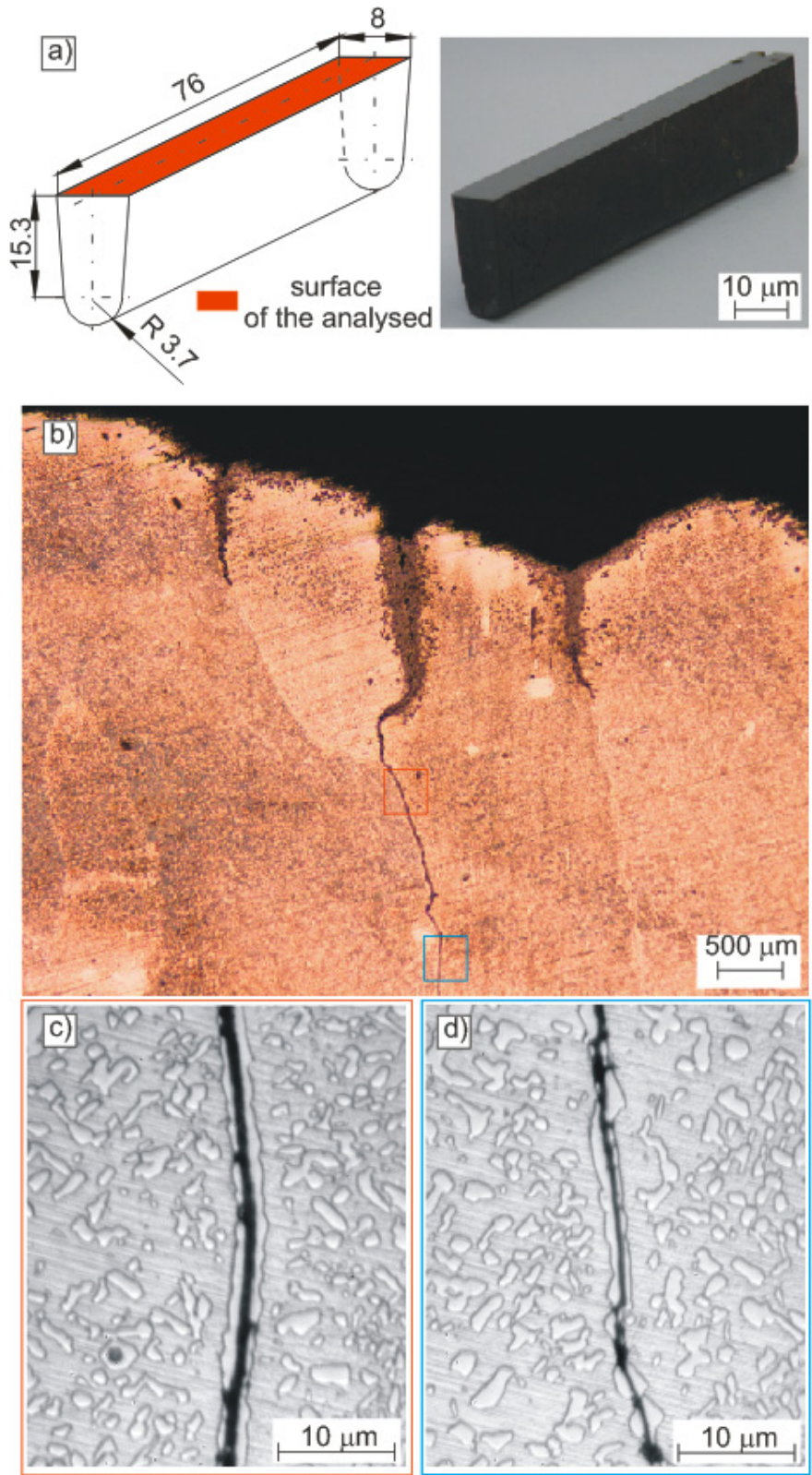

Fig. 11. Cracks in a carbonised rib made of austenitic steel cast after 75 cycles of thermal fatigue (light microscopy): a) rib, b) macro-structure of cracks, c) and d) micro-structure of the selected fragments of cracks

\section{Summary}

Cracking of the tooling elements being used in carburising furnaces is an unavoidable process. The micro-stresses that develop during rapid cooling due to differences in the values of thermal expansion coefficients for the phases of austenitic steel cast, of which the tooling is being made, are indicated as the cause of crack formation.

The stress components and the reduced stresses being numerically determined by the finite element method in respective phases of the adopted calculation models for the micro-structure of carbonised austenitic steel cast showed that the place of crack initiation is the carbides being located at the grain boundaries.
The crack formation is possible only in such carbides, the fragment of which is left uncovered by the austenitic matrix or they are directly under the layer of $\mathrm{M}_{7} \mathrm{C}_{3}$ carbide scale. Complete carbide coverage by the austenitic matrix prevents crack initiation.

The place of crack initiation in carbides at the grain boundaries depends on carbide coverage by the scale. In the case of the carbides being not covered by the scale and the austenitic matrix, crack formation occurs in the carbide area being located close to the carbide-austenitic matrix phase boundary. Location of the place of crack initiation changes when such carbides are being covered by the carbide scale; then, a crack is formed in the scale layer in a place being an extension of the carbide axis.

The analysis of the stresses being determined in the austenitic matrix and the carbides does not indicate any direct effect of permanent deformation of austenite in the vicinity of carbides on the cracking mechanism in the tested material.

The obtained images of the crack micro-structures in the carbonised and thermally fatigued rib show that cracks extend in such an element only through the carbides being located at the grain boundaries.

\section{Acknowledgements}

This study has been accomplished under the Research Project No 9/S/ IIT/2015 financed by a statutory activity grant of the Ministry of Science and Higher Education.

\section{REFERENCES}

[1] B. Piekarski, Austenitic steel castings used in the construction of carburising furnaces, Szczecin 2003.

[2] P. Gutowski, Study on the causes of cracking in pallets used in carburising furnaces. PhD thesis, Szczecin University of Technology, Szczecin 70310.

[3] A. Drotlew, B. Piekarski, J. Tuleja, Adv. in Mater. Sci. 5, 41-48 (2005).

[4] J. Tuleja, Influence of operational conditions on thermal fatigue of cast steel pallets in pusher carburizing furnaces. PhD thesis, Polish Naval Academy, Gdynia 81127.

[5] J. Tuleja, Arch. Foundry Eng. 10, 163-168 (2010).

[6] J. Tuleja, Arch. Foundry Eng. 8, 139-142 (2008).

[7] J. Tuleja, P. Gutowski, Arch. Foundry Eng. 6, 590-597 (2006).

[8] H.C. Furtado, I. Le May, Mat. Res. 1, 103-110 (2004).

[9] D. Brooksbank, K.W. Andrews, JISI. 6, 595-599 (1968).

[10] D. Brooksbank, K.W. Andrews, JISI. 4, 246-255, April (1972).

[11] Y. Sato, S. Akimoto, Appl. Phys. 50, 5285-5291 (1979).

[12] A.M. Huntz, Mat. Sci. Eng. A201, 211-228 (1995).

[13] H. Stuart, N. Ridley, JISI. 204, 711-717 (1966).

[14] H. Stuart, N. Ridley, JISI. 208, 1087-1092 (1970).

[15] J. Tuleja, Arch. Foundry Eng. 10, 205-210 (2010). 